\title{
Centros de desarrollo comunitario apoyados por el Programa Hábitat: una aproximación cualitativa
}

\section{Community Development Centers supported by Habitat-Sedesol: A qualitative approach}

\author{
Boris Graizbord \\ Rocío GonZÁLEZ-Alva*
}

\begin{abstract}
Public policy evaluation is part of governments' effort to comply with accountability, but also it is useful in decision making as it provides post fact knowledge about the outcomes of their actions. This paper presents an evaluation of Community Development Centers supported by Habitat-Sedesol. We are interested in capturing qualitative information on the perception that both beneficiaries and operators have about the opportunities offered by these centers to enhance cooperative and solidarity relations resulting in strengthening the social fabric. We conclude that despite having obtained economic benefits as well as having improved family relations, it is still necessary to make some additional efforts to create social capital in the wider community in which the centers are located.
\end{abstract}

Keywords: Community Development Centers, qualitative approach, focal groups, social capital.

\section{Resumen}

La evaluación de la política pública responde a la necesidad de transparentar la acción del gobierno, pero además es útil para tomar decisiones con conocimiento de los efectos o impacto que tienen sobre la población objetivo dichas acciones. En este trabajo se presenta sólo una parte de la evaluación realizada a los centros de desarrollo comunitario (CDC) apoyados por el Programa Hábitat a cargo de la Sedesol. Se trata de un análisis cualitativo a través de grupos focales para conocer la percepción que tienen los beneficiarios y los prestadores de servicios acerca de las oportunidades que ofrecen estos centros para fomentar relaciones de cooperación y solidaridad que lleven al fortalecimiento del tejido social. Se concluye que si bien se han obtenido beneficios individuales de tipo económico y en las relaciones familiares de los beneficiarios, aún es necesario fortalecer actividades que permitan la creación de capital social en las comunidades donde se localizan los CDC.

Palabras clave: centros de desarrollo comunitario, análisis cualitativo, grupos focales, capital social.

*El Colegio de México, México. Correos-e: graizbord@lead.colmex.mx, rgonzalez@colmex.mx. 


\section{Introducción}

México es un país predominantemente urbano. En el año 2005, siete de cada 10 mexicanos residían en ciudades. Esta concentración de la población ha dado lugar a un intenso proceso de urbanización de la pobreza. Las cifras elaboradas por el Consejo Nacional de Evaluación de la Política de Desarrollo Social (Coneval) estiman que 38.3\% de habitantes localizados en ámbitos urbanos (25 millones de personas) en el año 2005 se encontraba en situación de pobreza patrimonial. ${ }^{1}$ En este contexto socioespacial, el gobierno federal ha puesto en marcha estrategias y programas para guiar el desarrollo urbano y social en áreas fuertemente segregadas y donde se concentra la pobreza.

Así, en el año 2003 la Secretaría de Desarrollo Social (Sedesol) creó el Programa Hábitat con el propósito de articular los objetivos de la política social con los de la política de desarrollo urbano. Para la institución el interés consiste en avanzar hacia la superación de los rezagos y los profundos contrastes sociales en las ciudades y zonas metropolitanas, así como en contribuir a transformarlas en espacios seguros, ordenados y habitables.

El Programa está dirigido a enfrentar los desafíos de la pobreza urbana mediante la instrumentación de un conjunto de acciones que combinan, entre otros aspectos, el mejoramiento de la infraestructura básica y el equipamiento de las zonas urbano-marginadas con la entrega de servicios sociales y acciones de desarrollo comunitario en esos mismos ámbitos.

Mediante este programa se busca asegurar la concurrencia y la integralidad de los esfuerzos dirigidos a apoyar a la población urbana en situación de pobreza patrimonial, de acuerdo con los criterios establecidos por la Sedesol para medir la pobreza. ${ }^{2}$ El Programa Hábitat está particularmente enfocado en las necesidades de las mujeres, las nińas y los niños, los adultos mayores y las personas con capacidades diferentes. También tiene como tarea apoyar en la construcción de espacios con identidad y valor social, articular los barrios marginados y los asentamientos precarios al desarrollo de la ciudad, favorecer el ejercicio de los derechos de ciudadanía de la población asentada en esos ámbitos territoriales, y elevar la calidad de vida de los moradores de los numerosos centros urbanos del país, lo que sin duda resulta en un ambicioso propósito.

\footnotetext{
${ }^{1}$ La pobreza de patrimonio se define como "la insuficiencia del ingreso disponible para adquirir la canasta alimentaria, así como realizar los gastos necesarios en salud, vestido, vivienda, transporte y educación, aunque la totalidad del ingreso del hogar fuera utilizado exclusivamente para la adquisición de estos bienes y servicios" (http://www.coneval.gob.mx/coneval2/htmls/medicion_pobreza/ HomeMedicionPobreza.jsp? categorias=MED_POBREZA,MED_POBREZA-glosario).

${ }^{2}$ Los cuales se pueden consultar en la siguiente dirección electrónica: www.sedesol.gob.mx. Ver también el vínculo indicado en la nota anterior.
} 
Los esfuerzos del Programa Hábitat están dirigidos a las ciudades y zonas metropolitanas cuyo tamaño, ubicación y significación económica y social las convierten en puntos estratégicos para impulsar el desarrollo nacional y regional. Hábitat reconoce la necesidad de promover la creación de estructuras autosostenibles de desarrollo local y propone la operación de centros de desarrollo comunitario (CDC) como estrategia para ofrecer servicios integrales a la población e instrumentar acciones de beneficio social acordes con la condición y necesidades de las localidades urbanas, con la participación corresponsable de los gobiernos federal, estatal y municipal en colaboración con la población beneficiaria. ${ }^{3}$

Los CDC se inscriben en una de las tres modalidades o líneas de acción del programa Hábitat: la de desarrollo social y comunitario; las otras dos son mejoramiento del entorno urbano y promoción del desarrollo urbano. Los CDC son espacios físicos (inmuebles) que se constituyen de una o más aulas, así como de espacios para recreación y esparcimiento. ${ }^{4} \mathrm{~A}$ través de estos centros se ofrecen diversos servicios a la población. Los CDC se consideran espacios de encuentro y convivencia social, que refuerzan la identidad colectiva y que promueven el fortalecimiento de la organización social y el desarrollo comunitario. La operación de estos espacios comunitarios se dirige a la ampliación de capacidades laborales, por medio de cursos y talleres de capacitación en diferentes artes y oficios, cursos de desarrollo humano, talleres para mejorar la economía familiar, actividades artísticas, culturales y deportivas, así como servicios de atención, prevención y autocuidado de la salud.

\section{Contexto de la evaluación}

A mediados de 2007 y principios de 2008 realizamos una evaluación de los centros de desarrollo comunitario apoyados por el Programa Hábitat. ${ }^{5}$

${ }^{3}$ La población objetivo se constituye por los integrantes de los hogares asentados en los Polígonos Hábitat (zonas urbanas marginadas con alta concentración de hogares en situación de pobreza). El Programa potencia los subsidios federales con la aportación de recursos de los gobiernos de las entidades federativas y municipales y, en su caso, de los propios beneficiarios, para propiciar el desarrollo de las ciudades y de los Polígonos Hábitat (http://www.sedesol.gob.mx/index/index. php?sec=301102\&len $=1$ ).

${ }^{4}$ Conforme se establece en las Reglas de Operación (Sedesol, 2007), se entenderá por inmuebles apoyados por el Programa los que canalizan recursos para su construcción, ampliación, habilitación, rehabilitación y/o equipamiento, destinados a la prestación de servicios sociales. Y dada la existencia de inmuebles que ya por requisitos propios se encuentran cerca de la población objetivo, las acciones que se lleven a cabo con recursos del Programa, en particular las relativas a la modalidad desarrollo social y comunitario, se llevarán a cabo, preferentemente, en esos inmuebles.

${ }^{5}$ Además de los autores de este texto, participaron en el proyecto Adriana Larralde, José Luis González Granillo y Mariana Castillo, quien se encargó de coordinar la parte de organización de grupos focales. Para una presentación resumida de los resultados véase Graizbord et al. (2008). 
La idea de medir el desempeño no es nueva. Se convirtió en una línea de investigación en sí misma en los años sesenta del siglo pasado a partir del interés suscitado por la llamada guerra contra la pobreza en los países desarrollados, principalmente en Estados Unidos. Se pretendía conocer el efecto de los programas sociales para combatir la discriminación y otros males sociales (Scott y Marshall, 2005: 201). Pero en la actualidad los gobiernos, en especial los regímenes democráticos, hacen valer su compromiso con el principio de transparencia y se involucran sistemáticamente en informar al público sus acciones. Para que esto sea efectivo deben construir un sistema de monitoreo y evaluación que si funcionara eficazmente permitiría una retroalimentación con respecto a los resultados y consecuencias de tales acciones (Zall y Rist, 2004: 12), así como contar con insumos para las decisiones ex ante al diseñar estrategias de política (Graizbord, 1999). Según la OCDE (2002: 27, 21), el monitoreo es una función continua que debe proporcionar a los actores involucrados información con respecto a indicadores de intervención sobre el progreso y logros de objetivos en el uso de los recursos asignados a las acciones. Por su parte, la evaluación es una comprobación objetiva y sistemática del diseño, implementación y resultado de proyectos, programas o políticas en marcha o terminados. El propósito es determinar la relevancia y el cumplimiento de objetivos, la eficiencia, eficacia, e impacto y la sustentabilidad de lo que se evalúa. Asimismo debería proporcionar información útil y creíble que permitiera incorporar en el proceso de decisión de los donantes y los beneficiarios las lecciones aprendidas.

Con esto en mente, el objetivo general de esta evaluación, definido en los términos de referencia del proyecto solicitado al equipo de trabajo, fue analizar los procesos de gestión y operación de los centros de desarrollo comunitario con al menos un año de intervención del Programa Hábitat, para verificar cómo y en qué medida éstos y los servicios sociales que ofrecen inciden en el desarrollo comunitario (Sedesol, 2007: 8).

Los objetivos específicos fueron:

1. Analizar los procesos de gestión y operación de los CDC en términos de la modalidad de administración, el tipo de instituciones participantes, el funcionamiento, selección y oferta de servicios, y la participación comunitaria.

2. Evaluar los servicios sociales ofrecidos en los CDC apoyados por el Programa Hábitat, incluyendo un diagnóstico del tipo de servicios, su calidad, grado de utilización y el perfil de las personas atendidas y de quienes laboran en el CDC. 
3. Elaborar un diagnóstico del estado físico de inmuebles y equipamiento de los CDC y de la utilización de los espacios destinados a la provisión de los distintos tipos de servicios sociales.

4. Realizar un análisis financiero detallado de los CDC incluyendo costos operativos, costos por usuario de los servicios sociales, gastos de inversión fija y variable, fuentes de financiamiento y mezclas financieras.

5. Conocer la percepción de actores clave en la operación de los CDC, los beneficiarios y la creación y fortalecimiento de tejido social.

6. Identificar y explicar los factores de éxito o fracaso de los CDC.

Para el cumplimiento de estos objetivos se identificaron 220 centros (mapa I) a partir del diseńo de una muestra aleatoria representativa, y se siguió un enfoque de recopilación de información y análisis cuantitativo y cualitativo con base en instrumentos diseñados ex profeso para el trabajo en campo. Éstos responden estrictamente a líneas de investigación que se desprenden de los objetivos específicos mencionados.

Uno de los resultados generales más importantes de la evaluación se refiere a que la operación de los centros muestra una enorme heterogeneidad y diversidad en todo el país, es decir, en el tipo y cantidad de los servicios ofrecidos, en las formas de administración y funcionamiento cotidiano, en las características físicas de los espacios construidos y en el uso de los espacios; y finalmente, en términos de la eficacia con que operan.

\section{Mapa I}

\section{Distribución de los CDC de la muestra}

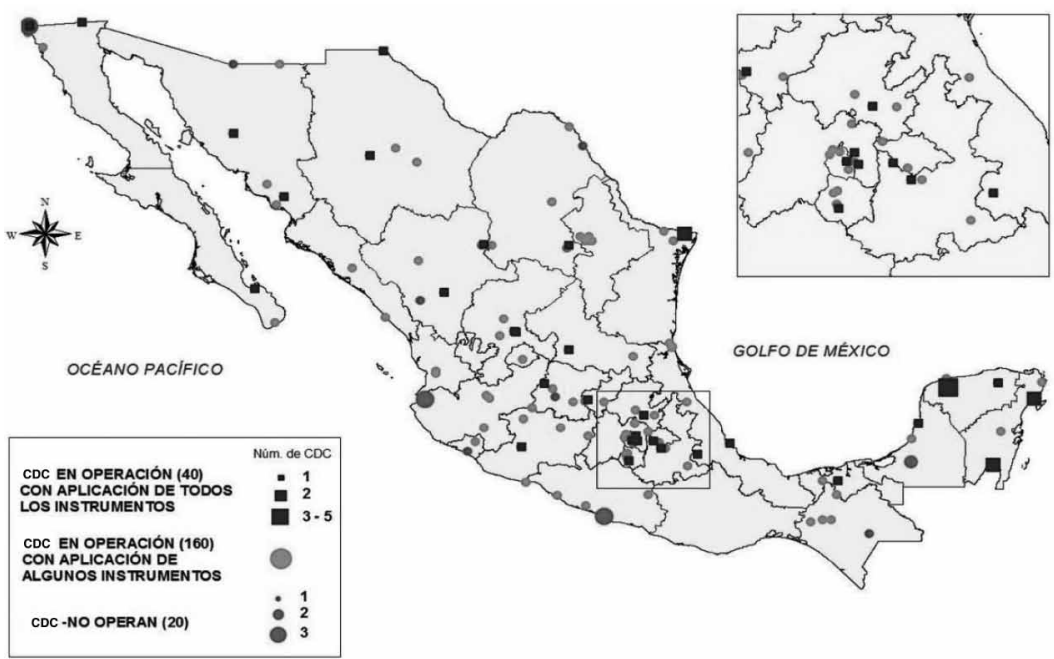

Fuente: Elaboración propia. 
El programa propone una estrategia que promueve la participación de diversos actores sociales, y si bien los resultados indican que así ocurre, la mayor participación es la de instituciones gubernamentales, especialmente el ayuntamiento. En efecto, la dirección de desarrollo social de los ayuntamientos, el sistema DIF municipal, los comités de planeación y desarrollo municipales, las direcciones del deporte, la cultura, la salud y la educación de los ayuntamientos son las que en general se responsabilizan de los CDC que conocimos. Otros actores responsables de la operación de los CDC son, en menor medida, los gobiernos estatal y federal, así como los prestadores de servicio social. Por último, figuran los habitantes de los barrios y las organizaciones de la sociedad civil (osc), según pudimos constatar a partir de la aplicación de instrumentos para obtener información, como las cédulas de información financiera y de operación. Y aunque uno de los propósitos fundamentales del Programa Hábitat es que la población beneficiaria asuma un papel protagónico en la operación de los centros, en general esto no ocurre. La comunidad interviene fundamentalmente en la definición de los cursos y servicios que se ofrecen, y en menor medida en los procesos de gestión y operación, es decir, en actividades que implican un mayor control de qué y cómo se hace. De hecho, la población beneficiada y las osc participan en las actividades de administración en sólo 14\% de los centros incluidos en la muestra, además, no se encontraron centros autogestivos. En la mayoría de los casos los centros se administran de manera pública y sólo la tercera parte de forma cogestiva, es decir, con la participación conjunta de la población o las osc, y el gobierno.

Otro resultado importante es la evidente complejidad en el funcionamiento de los centros, en el sentido de que es difícil definir qué actor es clave para dar como resultado una operación más o menos eficaz. Al analizar las modalidades de administración y el desempeño de los centros, encontramos que el hecho de que el CDC lo administre un actor del gobierno -municipal o estatal-, o que el centro sea cogestivo, no implica diferencias significativas en la operación, en términos de la cantidad de servicios ofrecidos, la poca o mucha respuesta de los usuarios, y las condiciones físicas de los inmuebles. Esto quiere decir que éste no es el único factor que define cómo funciona un centro, sino que existe una serie de elementos que en conjunto determinan las distintas formas de funcionamiento y el grado en que alcanzan los objetivos planteados; entre los que se cuentan los recursos financieros que ingresan a cada uno, la participación más o menos entusiasta de la comunidad, la organización social existente, la presencia de organizaciones sociales y políticas, la coordinación (entre los distintos órdenes de gobierno, en el interior de los municipios y de la comunidad con el ayuntamiento), la formación y capacidades de los trabajadores de los ayuntamientos, el uso de instru- 
mentos administrativos, entre otros. Sin embargo, encontramos que una proporción importante de CDC no cuenta con mecanismos formales de coordinación entre los actores involucrados en la gestión y operación, esto es, que sólo se realizan reuniones esporádicas para resolver asuntos coyunturales y visitas de supervisión no programadas.

Uno de los problemas más serios que enfrentan los CDC es la operación temporal. Para entender esta forma de operación hay que aclarar que existen centros con una actividad constante e intensiva a lo largo del año, y otros con actividad intensa en un periodo determinado, y muy baja o inexistente en otros, éstos últimos serían los que operan de forma temporal. Incluso se encontraron centros que por diversas causas (entre ellas, falta de recursos, mala planeación en su construcción y ubicación en zonas de riesgo natural), no iniciaron o detuvieron operaciones. Esta situación de operación temporal se debe en muchos casos a que los apoyos financieros que se otorgan a través del Programa Hábitat están sujetos a los ejercicios fiscales y reglamentación presupuestaria y, por ende, los recursos federales asignados al desarrollo social comunitario están supeditados a una temporalidad distinta a los ciclos de operación de los centros.

A través de inspecciones físicas in situ se detectó que existe una gran heterogeneidad física entre los CDC. La antigüedad del inmueble permite clasificar los centros inspeccionados en dos tipos: los construidos ex profeso por el Programa Hábitat (más recientes) y los que operan en inmuebles utilizados anteriormente para otros fines pero adaptados para funcionar como CDC.

Para conocer el perfil de los usuarios de los CDC, aplicamos 604 encuestas en 20 entidades federativas ${ }^{6}$ de acuerdo con la distribución de la muestra. Uno de los rasgos que comparten la mayoría de los CDC en todas las regiones y municipios del país es el perfil de los usuarios. Los resultados mostraron que $88 \%$ eran mujeres. La edad promedio de éstas fue de 38 años, mientras que para los hombres alcanzó los 40. Por las características del instrumento aplicado no se consideró incluir menores de edad, no obstante, una tercera parte de los servicios que se ofrecen tienen a éstos como población objetivo. Los anteriores resultados muestran en términos muy generales las características operativas, las condiciones físico-arquitectónicas y el perfil de los usuarios de los CDC.

En lo que sigue presentamos a detalle sólo los resultados de la parte de la evaluación correspondiente al objetivo específico 5: conocer la percepción de actores clave en la operación de los CDC, los beneficiarios y la creación y fortalecimiento de tejido social.

\footnotetext{
${ }^{6}$ Baja California, Baja California Sur, Campeche, Coahuila, Chihuahua, Durango, Guanajuato, Hidalgo, Estado de México, Michoacán, Morelos, Puebla, Querétaro, Quintana Roo, San Luis Potosí, Sonora, Tamaulipas, Veracruz, Yucatán y Zacatecas.
} 
El artículo presenta una reflexión expost que los autores han hecho de algunos de los resultados de la evaluación en la que participaron ${ }^{7}$ y tiene la finalidad de mostrar, desde una perspectiva cualitativa, ${ }^{8}$ las percepciones de los beneficiarios, prestadores de servicios y líderes comunitarios respecto a la contribución de los CDC a dos objetivos: 1) la formación de capital humano y 2) la construcción de capital social.

La idea de que las personas inviertan en sí mismas (o que la sociedad lo haga) tiene muchas implicaciones, pues cubre no sólo inversión en educación formal o capacitación en el trabajo, sino gastos en el hogar o en la comunidad para asegurar condiciones de salud infantil y materna, hasta inversiones para adquirir información sobre el mercado de trabajo. Pero, al mismo tiempo, el capital humano explica diferencias en sueldos y salarios, o la desigual tasa de desempleo según habilidades, lo que explica la asignación de recursos públicos en educación y capacitación. ${ }^{9}$ Por analogía con nociones de capital humano y capital físico -que representan capacitación y herramientas que realzan la productividad individual-, el capital social se refiere a aspectos de la organización social como las redes, normas y sentimiento de confianza social que facilitan la coordinación y cooperación entre individuos para beneficio mutuo. ${ }^{10}$

El texto continúa con una exposición de la metodología general que seguimos para acercarnos al cumplimiento de los objetivos específicos, entre los que se cuenta el análisis de la percepción de los actores clave sobre los beneficios de los CDC. Enseguida se describe la metodología y estrategia del trabajo de campo, es decir, la logística y organización de los grupos focales que se realizaron con los beneficiarios y prestadores de servicios y las entrevistas a líderes comunitarios. Después se presenta el análisis por actor y también de acuerdo con la temática referida a la creación de capital humano y social, y otros beneficios personales, familiares y comunitarios percibidos. Finalmente, se enuncian las conclusiones a las que llegamos.

\section{Metodología general de la evaluación}

El planteamiento metodológico general del trabajo ${ }^{11}$ consistió en combinar las técnicas de recolección de datos y análisis de los enfoques cuanti-

${ }^{7}$ Ver nota 5. Agradecemos la participación de Beatriz Acuña en la exploración de literatura necesaria para precisar algunos conceptos teórico-metodológicos.

${ }^{8}$ Un trabajo similar que también adopta un enfoque cualitativo y en particular el método de grupos focales es el de Garrocho y Brambila (2008).

${ }^{9}$ La teoría del capital humano la expuso Becker en 1964 (citado en Pearce, 1992: 188-189).

${ }^{10}$ Esta idea de capital social la ha desarrollado Putnam en dos textos que son la referencia clásica: 1993 et al., y 1995).

${ }^{11}$ La propuesta metodológica la definió la Dirección General de Evaluación y Monitoreo de los Programas Sociales (DGemps) de la Secretaría de Desarrollo Social (Sedesol). 
tativo y cualitativo. ${ }^{12}$ Se recopilaron datos estadísticos sobre los CDC y la población usuaria; pero también las historias y experiencias de los participantes en sus propias palabras.

La recolección de información se realizó para una muestra aleatoria de $220 \mathrm{CDC},{ }^{13}$ de un universo que consta de 521 centros apoyados por el Programa Hábitat en todo el país, entre 2003 y 2006. De este total se identificaron $200 \mathrm{CDC}$ que se encontraban operando y 20 que en ese momento se habían reportado sin operar. Para recopilar información de los usuarios de los centros que se encontraban en condición de operación se calculó una muestra de 800 usuarios y de 400 que habían participado en CDC que no se encontraban en operación. De manera que las unidades de análisis fueron los CDC y los usuarios de los mismos.

Los temas relevantes (líneas de investigación) para el levantamiento de la información se basaron en los objetivos específicos de la evaluación: 1) agentes que intervienen en la gestión y operación de los CDC, 2) recursos financieros aplicados, 3) características de la construcción y el equipamiento, 4) servicios, cursos y talleres que se ofrecen, y 5) percepción de los usuarios sobre los centros y sus actividades.

Como se mencionó, se diseñaron y utilizaron técnicas cuantitativas y cualitativas para recopilar la información y su posterior análisis. Los instrumentos de medición cuantitativos fueron las encuestas y las cédulas de inspección física y financiera. Los instrumentos cualitativos utilizados fueron las entrevistas en profundidad y la técnica de grupos focales.

Es conveniente destacar que el número originalmente planeado de instrumentos a levantar registró algunas modificaciones debido a situaciones de tipo logístico y de cambio de estatus de los CDC (de no operan a operan). Prácticamente se visitaron $195 \mathrm{CDC}$ considerados en la muestra y se realizó el levantamiento de los instrumentos de evaluación. El cuadro 1

12 En sociología encontramos argumentos a favor y en contra de la distinción entre los enfoques cuantitativo y cualitativo, y su reconciliación (Cortés, 2008). La distinción en parte es semejante a la que se da entre macro y microsociología. Mientras que la metodología cuantitativa se asocia a la epistemología positivista y se refiere a la recolección y análisis de datos numéricos como un proceso en la construcción y la comprobación/falsificación de teoría (De Vries, 1986: 20), la metodología cualitativa, asociada con la epistemología interpretativa (hermenéutica), tiende a referirse a formas de conseguir y analizar datos para entender o comprender el significado de los hechos y los valores que están atrás de la acción humana (Scott y Marshall, 2005: 538-539). Para una discusión accesible acerca de hechos y valores véase Hilary Putnam (1996). En pocas palabras, los métodos cualitativos se orientan a entender cómo los actores sociales ven, experimentan y construyen el mundo. Proporcionan acceso a los motivos, aspiraciones y relaciones de poder que condicionan/determinan cómo los lugares, la gente y los eventos se llevan a cabo y se representan. Un método es el de entrevistas cualitativas o grupos focales en el que no necesariamente se buscan respuestas típicas a preguntas predefinidas, sino recoger en detalle las opiniones e ideas de un número relativamente pequeño de individuos o grupos que se han seleccionado sistemáticamente para obtener de ellos pistas (luz) acerca de un área de interés sociológico particular (Johnston et al., 2000: 660).

${ }^{13}$ El diseño muestral fue realizado por la Dirección General de Geoestadística y Padrones de Beneficiarios (DGGPB) de la Sedesol. 
muestra el número de instrumentos validados y el porcentaje cubierto por tipo de instrumento.

\section{Cuadro 1 \\ Instrumentos recopilados y validados}

\begin{tabular}{|c|c|c|c|c|c|c|}
\hline Instrumentos & $\begin{array}{l}\text { Número a } \\
\text { levantar }\end{array}$ & $\begin{array}{l}\text { Número } \\
\text { modificado }\end{array}$ & $\begin{array}{l}\text { Entregados/ } \\
\text { capturados }\end{array}$ & $\begin{array}{l}\text { Porcentaje } \\
\text { cubierto }^{b}\end{array}$ & $\begin{array}{l}\text { Instrumentos } \\
\text { validados }\end{array}$ & $\begin{array}{c}\text { Porcentaje } \\
\text { cubierto }^{c}\end{array}$ \\
\hline $\begin{array}{l}\text { Encuesta a } \\
\text { usuarios }\end{array}$ & 800 & 700 & 661 & 94.4 & 604 & 86.3 \\
\hline $\begin{array}{l}\text { Entrevista a jefe } \\
\text { de unidad } \\
\text { Hábitat }\end{array}$ & 31 & 30 & 30 & 100.0 & 30 & 100.0 \\
\hline $\begin{array}{l}\text { Entrevista enlace } \\
\text { municipal }\end{array}$ & 117 & 114 & 101 & 88.6 & 101 & 88.6 \\
\hline $\begin{array}{l}\text { Entrevista a } \\
\text { coordinador }\end{array}$ & 40 & 40 & 34 & 85.0 & 32 & 80.0 \\
\hline $\begin{array}{l}\text { Entrevista a líder } \\
\text { comunitario }\end{array}$ & 60 & 40 & 34 & 85.0 & 34 & 85.0 \\
\hline $\begin{array}{l}\text { Cédula del CDC } \\
\text { (estado físico) }\end{array}$ & 200 & 195 & 186 & 95.4 & 186 & 95.4 \\
\hline $\begin{array}{l}\text { Cédula de } \\
\text { actividades }\end{array}$ & 200 & 195 & 147 & 75.4 & 147 & 75.4 \\
\hline $\begin{array}{l}\text { Cédula de } \\
\text { información } \\
\text { financiera }\end{array}$ & 200 & 195 & 151 & 77.4 & 144 & 73.8 \\
\hline $\begin{array}{l}\text { Grupo focal a } \\
\text { usuarios }\end{array}$ & 6 & 6 & 7 & 116.7 & 7 & 116.7 \\
\hline $\begin{array}{l}\text { Grupo focal a } \\
\text { prestadores de } \\
\text { servicios }\end{array}$ & 6 & 6 & 8 & 133.3 & 8 & 133.3 \\
\hline $\begin{array}{l}\text { Entrevistas a no } \\
\text { beneficiarios }\end{array}$ & 36 & 36 & 52 & 144.4 & 52 & 144.4 \\
\hline $\begin{array}{l}\text { Encuesta a ex } \\
\text { usuarios }\end{array}$ & 400 & $*$ & $*$ & $*$ & $*$ & $*$ \\
\hline $\begin{array}{l}\text { Grupo focal ex } \\
\text { usuarios }\end{array}$ & 6 & * & * & * & * & $*$ \\
\hline
\end{tabular}

a Se modificó el total de instrumentos a levantar debido a diversas situaciones atípicas.

${ }^{\mathrm{b}}$ Número de instrumentos entregados con respecto al número modificado.

c Número de instrumentos validados con respecto al número modificado.

* Al realizar las visitas, los CDC registrados como no opera ya estaban operando.

Fuente: Elaborado por el equipo de evaluación de El Colegio de México. 


\section{Metodología cualitativa y organización de los grupos focales}

El enfoque cualitativo procura alcanzar cierta profundidad, a la vez que llegar al detalle mediante una descripción y registro cuidadoso de las opiniones de los participantes. Está orientado a comprender la conducta humana desde el propio marco de referencia en que actúa, sin pretender hacer generalizaciones (Pérez, 1998). ${ }^{14}$

La investigación cualitativa consiste en descripciones detalladas de situaciones, eventos, personas, interacciones y comportamientos que son observables. Además, incorpora lo que sus participantes dicen, sus experiencias, actitudes, valores, creencias, pensamientos y reflexiones, tal y como las expresan ellos mismos (Pérez, 1998). Las técnicas más usadas en este tipo de investigación son: la observación participante, la entrevista cualitativa, el estudio de casos, el análisis de contenido o interpretación de textos, los perfiles, los grupos focales de discusión, etcétera.

En particular, el enfoque cualitativo lo utilizamos para recopilar las experiencias y percepciones de los participantes en la gestión y operación de los CDC, así como de los usuarios de dichos centros.

En el proceso de operación de los CDC hay actores clave de quienes depende su existencia y funcionamiento, los cuales a continuación se enlistan:

- El responsable del Programa Hábitat y por ende de los CDC en los estados, quien está encargado de promover y supervisar las acciones del Programa desde el ámbito estatal hacia los municipios.

- El enlace municipal, dado que es el ejecutor de esta estrategia de desarrollo social y urbano en el espacio local.

- El coordinador del CDC, porque además de formar parte del personal operativo del centro es responsable y coordinador de las actividades que se llevan a cabo cotidianamente en estos espacios.

- Los prestadores de los servicios, cursos y talleres. También forman parte del personal que trabaja cotidianamente en los CDC y tienen contacto directo con la población usuaria.

- Los usuarios de los CDC, pues son a quienes van dirigidas las acciones de los CDC.

- El líder de la colonia. Éste no es un actor que necesariamente se involucre en la operación de los CDC. Sin embargo, puede ser un informante clave para obtener conocimiento sobre el papel de los centros en la colonia.

${ }^{14}$ De hecho, el resultado y lo que se dijo en la sesión del grupo focal no es repetible, pero eso no implica que podamos interpretar y sacar conclusiones que puedan guiar una respuesta de política o bien concluir que las condiciones que se señalan reflejan una situación válida para una población semejante. 
Mediante la organización de grupos focales fue posible conocer la percepción de algunos de estos actores clave respecto de los CDC. Esta técnica responde a una estrategia de investigación que involucra intensas discusiones y entrevistas con pequeños grupos sobre algún aspecto en particular que se pretende esclarecer de manera más o menos detallada.

El grupo focal de discusión dirige su atención e interés en un tema específico de estudio e investigación que le es propio, por estar cercano a su pensar y sentir; y es de discusión porque realiza su principal trabajo de búsqueda por medio de la interacción discursiva y la contrastación de las opiniones de sus miembros. ${ }^{15} \mathrm{El}$ grupo focal es un método de investigación colectivista, más que individualista, y se centra en la pluralidad y variedad de las actitudes, experiencias y creencias de los participantes, y lo hace en un espacio de tiempo relativamente corto (Martínez, 2007).

El objetivo de la realización de estos grupos focales fue conocer los puntos de vista, las opiniones y las percepciones de los actores clave siguientes, así como intercambiar sus experiencias y vivencias: 1) usuarios y 2) prestadores de servicios

Para organizarlos se contó con la coordinación entre las autoridades federales de la Sedesol, las autoridades municipales (enlace municipal y coordinador de los CDC), los prestadores de servicios y los usuarios.

Se realizaron siete grupos focales con usuarios y ocho con prestadores de servicios ${ }^{16}$ en los estados de Baja California, Chihuahua, Guanajuato, Jalisco, Puebla, Quintana Roo y Yucatán. La selección de los CDC en los que se realizaron los grupos focales respondió a los siguientes criterios: 1) que los CDC seleccionados se ubicaran en estados del norte, centro $y$ sur de la República, y 2) que los CDC seleccionados fueran considerados por la Sedesol como centros ejemplares destacados y/o con problemas en su operación.

Los grupos focales en CDC que no operaban no se realizaron por dos motivos: 1) cambio de estatus del CDC de no opera a opera, y 2) no se completó el número de integrantes considerado como necesario para aplicar esta técnica.

\section{El desarrollo comunitario y el capital social como potenciadores de oportunidades de desarrollo}

Existe consenso entre los especialistas en que el desarrollo comunitario tiene sus orígenes en el colonialismo inglés de los años veinte (Gómez,

\footnotetext{
${ }^{15}$ Véase el Anexo, para una descripción del protocolo que se siguió en la realización de los grupos focales.

${ }^{16}$ Los prestadores de servicios son los maestros y maestras de los cursos y talleres, así como los médicos, dentistas, psicólogos, etcétera, que asisten y atienden a los usuarios de los CDC.
} 
2008). Hacia la década de los cuarenta se aplica en Estados Unidos y en los cincuenta lo institucionaliza la Organización de Naciones Unidas (ONU), el Banco Mundial y el Banco Interamericano de Desarrollo (BID) a nivel mundial. Son estas instituciones, además de la Organización de Estados Americanos (oEA), la Organización Mundial de la Salud (oms), la Organización Internacional del Trabajo (ОIT) y la Organización para la Educación, la Ciencia y la Cultura (UNESCO), en las que se construyó el marco conceptual y metodológico del desarrollo comunitario y, por ende, son la referencia clásica para su definición y análisis.

La ONU concibió el desarrollo comunitario como un proceso destinado a crear condiciones de progreso económico y social para toda la comunidad, con la participación activa de ésta. La suma de esfuerzos de una población y su gobierno para mejorar las condiciones económicas, sociales y culturales de las comunidades, e integrarlas en la vida del país contribuiría plenamente al progreso nacional (Ander, 2006: 35). El verdadero sentido que posteriormente se trató de dar al desarrollo comunitario fue de un proceso de mejoramiento en las condiciones de vida de la comunidad a través del apoyo de los gobiernos.

El desarrollo comunitario como política pública tuvo sus inicios en las zonas rurales y posteriormente se dirigió a las áreas urbanas, pero ha sido llevado a escala nacional, regional, provincial y barrial. Algunas estrategias para alcanzar el desarrollo comunitario se basan en la organización para la movilización de la población, la planificación para lograr las metas de la comunidad, la financiación mediante la obtención y empleo de recursos externos públicos y privados para ayudar a la comunidad social y económicamente, así como el adiestramiento de técnicos y de las comunidades en general. En el marco de los esfuerzos de desarrollo nacional, el financiamiento externo tiene como fines la movilización de la población considerada como un recurso para el desarrollo y su integración a la vida productiva en tanto se le proporcionen estructuras institucionales adecuadas, mediante las cuales se logre la integración de programas locales con los esfuerzos del desarrollo nacional (Ware, 1966).

En cuanto al término capital social, en la literatura sociológica (Portes, 1998: 3) se insiste que el origen conceptual del mismo y el primer análisis contemporáneo sobre el tema lo produjo Bourdieu, quien lo definió como "El agregado de actividades o potenciales recursos los cuales están conectados a la posesión de una red duradera de relaciones más o menos institucionalizadas de mutuo acuerdo o reconocimiento" (1985: 249). Sin embargo, Bebbington (2007) se pregunta si puede este concepto trasladarse a la política. Fue precisamente Coleman (1966) quien con ese propósito elaboró mucho antes este concepto para describir las relaciones que existen entre individuos tanto dentro de la familia como de la comu- 
nidad, mismas que ejercen una fuerte influencia en los logros educativos. Pero quien efectivamente popularizó el término fue Putnam (et al., 1993, 1995). En efecto, a diferencia de Bourdieu cuyo nivel de analisis es el individuo, y Coleman que se ocupa de caracterizar familias en términos de su estructura y su religiosidad, ${ }^{17}$ este autor enfatiza aspectos clave de la organización social: confianza, normas, redes, a partir de un involucramiento de los individuos en asociaciones voluntarias y actividades informales. A raíz de su trabajo, el concepto de capital social se concibe íntimamente ligado a una acción social que conduce a la gente a una mejoría en su situación económica.

En todo caso, la definición de Bourdieu contiene dos elementos fundamentales: 1) la relación social en sí misma que permite a los individuos demandar acceso a recursos que están en posesión de los asociados, y 2) la cantidad y calidad de los recursos.

A través del capital social, es posible que los actores tengan acceso directo a recursos económicos (préstamos, por ejemplo) ya que pueden aumentar su capital cultural a través de contactos con expertos, personas de nivel económico más alto o también pueden integrarse a organizaciones que les apoyan con acceso a recursos.

Bourdieu remarca que los resultados de la posesión de capital social o cultural es reductible al capital económico, en tanto que los procesos que dan lugar a estas formas alternativas no lo son. Es decir, el capital social representa la capacidad de los actores para lograr beneficios en virtud de la pertenencia a redes sociales o a otras estructuras sociales.

Desde esta perspectiva, las acciones del Programa Hábitat tienen como objetivo sumarse a los esfuerzos de los gobiernos estatales y municipales, organismos de la sociedad civil y de los propios vecinos para construir espacios que contribuyan al desarrollo integral de las personas, sus familias y sus comunidades. Este programa reconoce la necesidad de apoyar a través de los CDC la creación de estructuras autosostenibles de desarrollo local. La comunidad, al hacer suyo el CDC, debe garantizar que las acciones realizadas correspondan a las expectativas de desarrollo local y sean congruentes con los esquemas de superación de la pobreza.

Para alcanzar esta meta se plantean los siguientes propósitos, ambiciosos por cierto, de los CDC:

- Ofrecer servicios preventivos y atención primaria a grupos de población prioritaria (mujeres, niñas y niños, jóvenes, personas adultas mayores o con capacidades diferentes) en aspectos básicos para su desarrollo

${ }_{17}$ Véase al respecto http//:www.socialcapitalresearch.com/contemporary-authors.htm, 12 de febrero de 2011. 
integral, como la salud, la educación no formal, las actividades culturales, recreativas y deportivas, la capacitación para el trabajo y el fomento de proyectos productivos.

- Fortalecer el tejido social mediante la promoción de la organización y participación de los vecinos.

- Impulsar la construcción del sentido cívico, con énfasis en el conocimiento y ejercicio de los derechos ciudadanos, que son la base para una vida social justa y armónica.

- Propiciar la transformación de actitudes y conductas que tiendan a mejorar las relaciones interpersonales de las familias y vecinos.

- Impulsar la equidad de género y promover la participación de las mujeres en la toma de decisiones de las diferentes acciones comunitarias.

- Impulsar la instrumentación de medidas colectivas que refuercen la seguridad de las personas y familias del barrio o colonia a partir de su organización e interacción en el CDC (Sedesol, 2005).

Un resultado positivo, entonces, sería crear espacios de convivencia en los que, por un lado, se desarrollen relaciones interpersonales basadas en la confianza entre miembros de la comunidad y, por otro, se logre la capacitación que permita ampliar las habilidades de los participantes para incrementar los ingresos familiares a partir del aprendizaje de oficios productivos.

Bourdieu (1985) y Coleman (1966) enfatizan el carácter relativamente intangible del capital social, porque mientras que el capital económico de la gente se encuentra en cuentas bancarias y el capital humano está en sus cabezas, el capital social es inherente a la estructura de sus relaciones sociales. En este contexto, la función de los CDC es proveer un espacio comunitario que permita que los usuarios que aprovechan esta oferta y asisten a estos inmuebles aprendan oficios o practiquen alguna actividad, e inicien un proceso de relaciones con sus vecinos, ampliando el potencial de la comunidad para generar redes de confianza entre sus miembros. Pues, como señalan esos autores, una fuente de capital social es la confianza entre los demandantes y los poseedores de recursos.

De este modo, en este trabajo se entiende el capital social en el nivel de analisis comunitario que adopta Putnam (et al., 1993, 1995). En efecto, se trata de desarrollo en términos de membresía a asociaciones, participación política y actividades cívicas. En este sentido, como se desprende de Durston (2000), el capital social se concibe como la institucionalidad formal e informal que integra normas culturales de confianza entre individuos, con las prácticas de cooperación entre todos los miembros de un sistema. 


\section{Percepción de actores clave con respecto a los beneficios de los centros de desarrollo comunitario}

$\mathrm{Al}$ ser los CDC una de las estrategias instrumentadas del Programa Hábitat, a través de su modalidad de desarrollo social y comunitario, ${ }^{18}$ para "ampliar las destrezas, competencias, capacidades y oportunidades de las personas y de los hogares en situación de pobreza patrimonial y a fortalecer el tejido social de las comunidades", se consideró necesario analizar la percepción de los actores clave respecto a la consecución de estos objetivos. El referente a la ampliación de destrezas, competencias, capacidades y oportunidades de los usuarios se relaciona directamente con la creación de capital humano. ${ }^{19}$ Mientras que el de fortalecer el tejido social de las comunidades está encaminado a la creación de capital social. ${ }^{20}$ De aquí que las preguntas fundamentales que guiaron esta parte de la investigación fueran las siguientes:

1. ¿Cómo y en qué medida los CDC amplían las capacidades, destrezas, competencias y oportunidades de los usuarios? (capital humano)

2. ¿Cómo y en qué medida los CDC fortalecen el tejido social mediante la promoción y participación de los vecinos? (capital social)

3. ¿Cómo y en qué medida los CDC fomentan la creación de redes y vínculos sociales entre los usuarios? (capital social)

4. ¿Qué otros beneficios brindan los CDC a la población beneficiaria-de acuerdo con su percepción - en los ámbitos personal, familiar y comunitario? (capital humano y social)

\subsection{Percepción en relación con la creación de capital humano}

En este apartado nos enfocamos en la percepción de los actores clave (usuarios y prestadores de servicios) sobre la contribución de los CDC en la ampliación de destrezas, competencias, capacidades y oportunidades de las usuarias. ${ }^{21}$

Para las usuarias el hecho de obtener algún tipo de enseñanza adicional, emprender o desarrollar alguna habilidad, así como interactuar y

${ }^{18}$ Véase los Términos de Referencia: Sedesol, 2007: 4.

${ }^{19}$ La escolaridad, la atención médica, un curso de computación, etc., se pueden considerar como inversiones en capital humano en el sentido de que se relacionan con incrementos en el ingreso, beneficios en salud y mejores condiciones de vida en general (Becker, 1993).

${ }^{20}$ Operativamente, el capital social se refiere al conjunto de activos que son consecuencia de las relaciones de unos con otros y de la participación en las organizaciones sociales. Tales relaciones facilitan el acceso a otros recursos. Para una referencia del papel que tiene el capital social en la superación de la pobreza véase Bebbington (2005).

${ }^{21}$ Nos referimos a usuarias dado que $88 \%$ de los asistentes a los CDC son mujeres, de acuerdo con la encuesta de usuarios. 
compartir tiempo y experiencias con otras personas de la comunidad son elementos que contribuyen al desarrollo tanto de su vida personal como familiar.

Las usuarias que participaron en los grupos focales reportan beneficios económicos para ellas y sus familias. Comentan que asisten a los CDC para aprender algún oficio, entre otras razones:

Más que nada [el centro] es para obtener ingresos económicos, para poder apoyarnos nosotras mismas. Para desenvolvernos más como personas, para tener ingreso, para tener una ayuda en [el] hogar (Grupo focal con usuarios, Guanajuato, $12 / 11 / 2007)$.

[Sirve para] ayuda económica de uno mismo, de nuestra familia, para salir adelante, que a veces uno no estudia una carrera completa, sirve para mucho, para ser alguien [... (Grupo focal con usuarios, Baja California, 11/16/2007).

[A partir de la apertura del centro] la comunidad no ha cambiado, hemos cambiado las personas, quienes vienen a estudiar y quienes usan los servicios [...] cambia su economía, cambia su forma de ser (Grupo focal con usuarios, Baja California, 11/16/2007).

Sí son muy útiles [los CDC, son] de mucha utilidad para aprender y poder obtener un ingreso económico. Hay muchas personas [que se han capacitado en los CDC] trabajando, recibiendo beneficios económicos. Todo lo que estamos aprendiendo nos [está sirviendo] mucho (Grupo focal con usuarios, Guanajuato, 12/11/2007).

[Sí es muy útil] yo no sabía costurar, y ya hasta le he hecho sus uniformes a mis sobrinos, a mis hijos (Grupo focal con usuarios, Yucatán, 07/11/2007).

Yo vengo a belleza y ya trabajo en mi casa. Económicamente ayuda bastante (Grupo focal con usuarios, Yucatán, 07/11/2007).

Los beneficios reportados por las usuarias ponen de manifiesto que, hasta el momento en que se realizó la evaluación, los CDC han aportado un espacio de aprendizaje y formación individual, mediante lo cual lo que ellas aprenden en los CDC puede contribuir económicamente en sus hogares. Pero, además, también lo perciben como un beneficio en su desarrollo personal, es decir, puede detectarse la formación de capital humano. El desarrollo de capital económico es un tanto incipiente pero se considera como un avance por las usuarias en el presupuesto familiar y, por tanto, en sus condiciones de vida.

Además del ingreso económico directamente obtenido en dinero extra a partir de practicar los oficios y habilidades aprendidas, las usuarias detectan ahorros mediante la realización por su propia cuenta de materiales y servicios para ellas y sus familias, lo que les permite reducir los gastos 
familiares para cubrir ciertas necesidades, con la opción de usar lo ahorrado en adquirir otros requerimientos del hogar.

Los prestadores de servicios que participaron en los grupos focales coinciden con las usuarias citadas en cuanto a que los CDC están mejorando las oportunidades de obtención de ingresos económicos de quienes asisten a los cursos de capacitación para el trabajo, como se aprecia en los siguientes testimonios:

Tengo un programa de empresa, mis alumnas fueron becadas por el servicio nacional de empleo. Estamos siendo como un puente, nosotros les damos la capacitación, el servicio nacional les da las becas y las mandamos a capacitación a las empresas [...] de 20 becas que nos dieron, se quedaron 11 ex alumnas de Lomas del Paraíso a laborar. Pues creo que sí estamos funcionando (Grupo focal con prestadores de servicios, Jalisco, 11/10/2007).

Una alumna que cuidaba a su familia, tenía mucho estrés [...] porque no sabía cómo sacar adelante a su familia. Terminando el curso ella se empleó, está trabajando en una estética y está super cambiada. Antes era muy nerviosa, temblaba todo el tiempo. Otra chica ya acondicionó su sala (para servicios de belleza) y está trabajando en su casa. Hay muchas personas así. Y el inglés y la computación ayudan aquí en la playa a la gente, para que se pueda emplear (Grupo focal con prestadores de servicios, Quintana Roo, 07/11/2007).

Entre alumnas se juntan para empezar a poner sus negocios. Los cambios son que la gente ya está trabajando y percibiendo ingresos (Grupo focal con prestadores de servicios, Quintana Roo, 07/11/2007).

Mis alumnas todo lo que han elaborado, lo han vendido. Hacen sus arreglos de migajón, ahorita hicieron pińatas, sus cuadros de repujado y todo lo venden (Grupo focal con prestadores de servicios, Yucatán, 07/11/2007).

Tengo alumnas que han iniciado su negocio y les ha ido muy bien. De hecho, dentro de los alumnos de agosto a esta fecha, tengo alumnos que han iniciado sus pequeños negocios de velas decorativas y les ha ido muy bien. Entonces sí, sí les ayuda bastante y me da mucho gusto (Grupo focal con prestadores de servicios, Jalisco, 11/10/2007).

Por su trascendencia destacamos aquí ejemplos de oportunidades de empleo y otras formas de generación de ingresos para adultas mayores:

Ellas se están capacitando para el trabajo, la principal problemática que ellas ven al principio es el costo, después la edad, decían “¿cómo voy a trabajar yo?” Afortunadamente yo hablé con el oficial de trabajo y le dije que me diera la oportunidad de meter a las personas que ya fueran mayores de edad como becarias, para que el empresario le abriera las puertas y durante dos meses vieran lo que ellas pueden hacer (que es lo que les dan de capacitación práctica laboral). Entonces me ha dado muchísimo gusto que señoras de 55 años se quedan laborando, estoy muy emocionada porque desde un principio se le metió a este proyecto, que no fuera nada más corte y confección, sino que ellas ya salgan a trabajar o se auto- 
empleen. Y eso ha dado resultado (Grupo focal con prestadores de servicios, Jalisco, 11/10/2007).

Las y los beneficiarios, prestadores de servicios, las y los líderes comunitarios, así como las usuarias encuestadas coincidieron en señalar que los CDC contribuyen principalmente a mejorar la situación económica y el desarrollo personal y familiar. En otras palabras, los CDC están incidiendo -aún de manera elemental- en la creación de capital humano.

\subsection{Percepción respecto a la creación de capital social}

En este apartado se destaca la percepción de los actores mencionados respecto a la capacidad de los CDC para fortalecer el tejido social de las comunidades, a través del fomento de vínculos sociales entre los usuarios y la promoción de la organización y participación vecinal.

En los centros se establecen relaciones de apoyo mutuo entre las usuarias, lo cual contribuye a desarrollar la confianza y crear vínculos sociales dentro de la comunidad, como sugieren los siguientes testimonios obtenidos a través de los grupos focales:

\footnotetext{
Nos conocimos aquí y a partir de entonces la relación ha sido buena. Convivimos más, nos apoyamos más. Yo me imagino que si ella sabe algo que me interesa [aprender], me apoyaría (Grupo focal con usuarios, Quintana Roo, 07/11/2007).

Tengo compañeras que conocí aquí mismo que me cuidan a los niños (Grupo focal con usuarios, Chihuahua, 18/10/2007).
}

Los prestadores de servicios también expresaron sus opiniones sobre la manera en que los CDC contribuyen al fortalecimiento de vínculos sociales. Algunos ejemplos en este sentido pueden leerse a continuación:

[En el curso de corte y confección] el año pasado tuve una alumna, que llevábamos tres meses del curso cuando ella se puso a fabricarle al papá unas chamarritas [que el señor vendía]. Ella me dijo "maestra necesito hacer unos patrones, para fabricar unas chamarritas, ¿cree que pueda?”, “¿Claro que puedes!”, le dije y se puso a hacerlos y en diciembre no se dio abasto para surtirle al papá. Entonces ella misma le habló a otra compañera y entre compañeras se ayudaron: "Tú cortas, yo armo y mi papá, las vende”. Entonces, el señor dejó de comprar a otras personas, eran unas chamarritas que a él se las daban muy caras, y aquí las alumnas empezaron a trabajar juntas [...] y aparte sobre todo la integración que lograron como personas (Grupo focal con prestadores de servicios, Jalisco, $11 / 10 / 2007)$.

Aquí, los compañeros no me dejarán mentir [...] ha sido un proyecto muy provechoso, ayuda muchísimo, porque aparte del adiestramiento que les damos [...] un psicólogo les da "manejo del estrés laboral", la gente no sólo se integra a la capacitación para el trabajo, sino que también se va integrando a la sociedad. 
Emocionalmente la gente sale de aquí muy diferente (Grupo focal con prestadores de servicios, Jalisco, 11/10/2007).

Aquí no sólo aprenden el adiestramiento que nosotras impartimos, ¿̨no? Sino que aquí las personas adquieren un poco más de seguridad [...] aprenden a relacionarse con las demás personas y por ende aprenden cosas nuevas [...] porque entre ellas [las alumnas] luego se dan consejos, tratan asuntos familiares. Yo por eso veo que el centro de desarrollo tiene un papel muy importante [...] [Y, al hablar de otro tema] sí [se han fortalecido los lazos de amistad entre las usuarias] incluso muchas, aunque eran vecinas, no tenían comunicación, no se llevaban, ni nada, y ahora sí [ahora la situación ha cambiado] (Grupo focal con prestadores de servicios, Yucatán, 07/11/2007).

Hay coincidencia entre los usuarios y los prestadores de servicio en que la existencia del CDC contribuye a la creación o fortalecimiento de vínculos sociales, pero fundamentalmente entre las personas que asisten a los cursos y talleres.

En el proceso hacia la creación de capital social, los CDC muestran un avance en la promoción de vínculos sociales basados en la confianza. Sin embargo, de acuerdo con la percepción de actores clave, en esta primera etapa de funcionamiento de los CDC, no se ha trascendido este nivel. Es decir, en cuanto a una organización y participación comunitaria de los vecinos no se percibieron efectos importantes.

No se ha logrado consolidar la organización y participación comunitaria en el manejo o gestión de los CDC; una razón puede ser el corto tiempo que llevan funcionando. Solamente encontramos que, de acuerdo con las percepciones de los diferentes líderes entrevistados, hay una gama de usos de los CDC por parte de la población: algunos centros se han utilizado como albergues y/o centros de acopio en casos de desastres naturales, para impartir pláticas hacia grupos vulnerables, de temas como violencia contra las mujeres, para el uso de diferentes programas públicos e incluso como casilla electoral. Asimismo, para la convivencia de la comunidad y, en mucho menor medida, para actividades religiosas y políticas.

Se reconoce, sin embargo, en la percepción de los participantes, que los centros han contribuido a mejorar la imagen de la colonia. Esta opinión se aprecia en los siguientes extractos de los grupos focales con usuarios y con prestadores de servicios:

La comunidad ahorita es más alegre, más libre de borrachos, más limpia. Ha cambiado para bien. Estaban empezando a venir muchachos a jugar arrancones con sus motos, y ahora, no [...] ahora ya hay más control, está muy tranquilo (Grupo focal con usuarios, Quintana Roo, 08/11/2007).

El centro le ha dado vida a la colonia. Hubieran visto cómo era antes, estaba todo lleno de tierra. El cambio fue total, ya que el índice [sic] de inseguridad era demasiado alto, no podíamos andar por la calle a las 7 de la noche y ahora son las 
9, las 10, las 11 y hay gente jugando, participando, hay luz. El centro se cierra a las 8 y media de la noche pero las actividades siguen afuera, en torneos [...] los chicos se siguen involucrando. Aparentemente no se ve un cambio, pero nada más que digas de una pandilla, la mitad se fue a jugar, ya es una ganancia (Grupo focal con usuarios, Puebla, 15/11/2007).

Los testimonios presentados en esta sección sugieren que la población atendida -si bien no la totalidad-se beneficia no sólo de los cursos y talleres que se imparten en los CDC, también de otras actividades que alcanzan a miembros de la comunidad que no asisten con regularidad al centro.

En síntesis, la percepción manifiesta de los usuarios, prestadores de servicio y líderes de la comunidad sugiere que los CDC no han incidido en el fortalecimiento del capital social más allá del fomento de vínculos sociales a través de la interacción cotidiana en los centros, y que no se ha logrado aún su involucramiento y participación como gestores de este proyecto.

\subsection{Otros beneficios personales, familiares y comunitarios percibidos}

En este apartado abordamos el tema de otros beneficios de los CDC reportados por los actores clave en los ámbitos personal, familiar y de la comunidad. Estos actores mencionaron que los mayores beneficios que han recibido se encuentran en los ámbitos personal y familiar, principalmente. Algunos beneficios menos significativos se han orientado hacia la comunidad. En general, las beneficiarias y los prestadores de servicios coincidieron en señalar que los CDC han contribuido sobre todo al desarrollo personal y familiar y de alguna manera a mejorar su situación económica.

Como se pudo constatar en el trabajo de campo, las actividades que se brindan en los centros para nińos y adolescentes cumplen con una labor complementaria a la que desarrollan en la escuela, debido a que en los centros pueden incursionar en múltiples actividades que en el corto y mediano plazos les podrán retribuir algún beneficio para el mejoramiento de su desempeño escolar y, por tanto, en la calidad de vida y formación de capital humano.

Las usuarias que participaron en los grupos focales reportan que la asistencia a los centros les ha traído beneficios en su persona y su familia. No solamente porque les permite ahorrar algunos gastos y generar ingresos derivados de los oficios aprendidos, por ejemplo los cursos de belleza y corte y confección, sino también porque les ayuda a mejorar las relaciones familiares. Los siguientes testimonios permiten apreciar lo anterior:

Yo, a mi edad empecé a sufrir de depresión, muchos nervios, insomnio. Para mí es una terapia sentirme útil todavía. Porque [cuando nacieron mis] hijos me dedicaba sólo a ellos y luego vinieron los nietos y también [me dediqué] sólo a ellos, 
no tenía tiempo para mí. [Antes de empezar a venir al centro] yo ya estaba en un rincón de mi cuarto, con la tele prendida (Grupo focal con usuarios, Quintana Roo, 07/11/2007).

[...] a las personas de la tercera edad les cayó re bien porque está el grupo para las personas mayores, y no pues traen otras caras las personas, de como las vemos ahora, viniendo todos los días que a bailar, o a ir de paseo (Grupo focal con usuarios, Baja California, 16/11/2007).

[...] y yo he visto que [a] compañeras incluso [el beneficio se nota] hasta en la seguridad. Porque uno viene muy cohibido, entra a los cursos solo y ahí va agarrando confianza. Yo he visto los cambios que se dan en las mujeres, y se ven más guapas (Grupo focal con usuarios, Quintana Roo, 7/11/2007).

[A las mamás] les ha ayudado mucho al contar con una opción complementaria para su economía familiar, porque a través de los cursos pueden trabajar, a veces sólo laboraba el padre de familia, o bien pueden ahorrar [...] por ejemplo en los cursos de belleza, ellas pueden cortar el cabello a sus familiares, sin tener que pagarle a alguien más (Grupo focal con prestadores de servicios, Guanajuato, 12/11/2007).

Las personas quieren aprender para superarse. Es para el beneficio de las familias. Aquí más que nada vienen muchas familias. Si uno viene a clase aprovecha y los nińos juegan [estos centros se crearon] básicamente para el beneficio de la comunidad. De los cursos que venimos a tomar podemos emplearnos, para mejorar el ingreso familiar. Puedes hacer manualidades y venderlas (Grupo focal con usuarios, Veracruz, 28/11/2007).

Además, la asistencia de los y las usuarias a los CDC contribuye a elevar la autoestima y a obtener seguridad emocional, como se infiere de los siguientes testimonios:

[Los cursos] son muy importantes para la gente porque muchas de ellas llegan pensando que no son capaces de realizar una actividad determinada, y cuando la toman aquí y ven que sí pueden, en primer lugar les sube su autoestima porque se dan cuenta que son útiles y además pueden percibir un ingreso realizando ese trabajo (Grupo focal con prestadores de servicios, Guanajuato, 12/11/2007).

Además de maestros, estamos jugando el rol de amigos, de psicólogos porque los coordinadores nos pidieron que también observáramos a nuestros alumnos y detectáramos si existen problemas y qué tipo de problemas [...] jugamos estos roles y de eso las madres se dan cuenta. Conmigo las madres se acercan y me [preguntan que] qué les [hacemos a] las niñas [que] llegan cambiadísimas [y que] andaban insoportables días antes. Y uno no hace nada, simplemente la recreación, el hecho de que estén aquí cambia su estado de ánimo (Grupo focal con prestadores de servicios, Jalisco, 11/10/2007).

Un hallazgo fue detectar casos de maltrato a mujeres en sus relaciones de pareja, los cuales han sido canalizados y/o atendidos en los CDC en la medida de lo posible por los prestadores de servicios. En efecto, en algunos centros se están dando orientaciones sobre estos y otros temas a grupos vulnerables: 
[También tenemos] psicólogos [que] les dan talleres a nuestras alumnas, las orientan sobre violencia intrafamiliar, sobre quererse a sí mismas, y eso hace que, bueno, aparte que lo están recibiendo por todos lados, la mujer trate de superar sus problemas [...] esto también ayuda mucho (Grupo focal con prestadores de servicio, Yucatán, 07/11/2007).

Yo tengo dos alumnas que [sic] sus maridos no saben que vienen a los cursos, uy porque si se enteran se enojarían. A veces me llegan 15, 20 minutos tarde y si les reclamo por qué no llegan puntualmente que se me retrasan, me contestan: "Maestra, es que mi marido no se iba y yo tengo prohibido salir" (Grupo focal con prestadores de servicios, Jalisco, 11/10/2007).

Han llegado señoras con los ojos morados y me las han sacado del salón los maridos y nos hemos tenido que enfrentar. Yo me he enfrentado, porque les he dicho: sabe qué, respete los derechos de esta señora y me he metido en muchísimas cosas, pero las canalizamos hasta donde se ha podido. Las hemos canalizado al DIF, les hemos conseguido abogados [...] (Grupo focal con prestadores de servicio, Jalisco, 11/10/2007).

A pesar de que los beneficios que las usuarias perciben son principalmente personales y familiares, los centros también propician la transformación de actitudes y conductas que tienden a mejorar las relaciones interpersonales de vecinos. Los CDC permiten que las asistentes a los cursos aprendan a relacionarse con las demás personas del barrio, a fortalecer lazos de amistad y a establecer mecanismos de ayuda mutua y compañerismo. Esto, según las percepciones tanto de las usuarias como de las y los prestadores de servicios que participaron en los grupos focales:

[La labor de los CDC] es importante por cómo está ahorita la juventud. No tienen ocupación y hay personas que les regalan dulcecitos con droga. No tienen dónde sacar su fuerza. En cambio aquí vienen y patinan, andan en bicicleta, juegan. Se alejan de las banditas, y eso es bueno (Grupo focal con usuarios, Quintana Roo 07/11/2007).

Los jóvenes vienen a aprender en lugar de meterse en problemas. Es bueno porque se alejan del vandalismo (Grupo focal con usuarios, Yucatán, 07/11/2007).

Yo he tenido personas que llegan y no hablan, que habiendo sido muy reservadas cuando llegan, terminan siendo la líder del grupo [...]. Hay una que el papá la trajo y dijo: "Ya no la quiero ver en la calle, ya no la quiero ver drogarse, la dejo a ver que hagan algo por esta nińa", así me dijo [...]. Y ahorita [después de capacitarse en corte y confección] ella ya está trabajando y le dejaron a su cargo una máquina de 15 cabezas que no es nada fácil [...]. Hasta se me enchina la piel, porque es bien emocionante, el día del examen vinieron el papá, la mamá y sus hermanos, le trajeron flores y ellos me decían a mí que no creían que ella fuera a cambiar en tan poco tiempo [...] pero ella nunca faltó a clases (Grupo focal con prestadores de servicios, Jalisco, 11/10/2007). 
Estas opiniones sugieren que a partir de la interacción cotidiana que mantienen los usuarios al asistir a un CDC, se desarrollan y amplían los vínculos entre vecinos, situación que puede coadyuvar a su vez a mejorar la organización de los habitantes de los barrios y por ende de la comunidad. Se observa además otro tipo de conexiones de índole laboral y comercial pues, como pudimos apreciar, entre las mismas usuarias y otros miembros de la comunidad existe un intercambio de servicios u oficios aprendidos en los CDC.

\section{Conclusiones}

Conocer la percepción sobre los beneficios de los CDC fue el objetivo principal de este aspecto de la investigación. La atención a las respuestas de los participantes en los grupos focales se centró principalmente en dos temas: los beneficios percibidos por los usuarios que consideramos elementos esenciales 1) para la creación de capital humano y 2) para la construcción de capital social.

El concepto de capital social (Ks) se ha combinado también con aspectos del capital cultural $(\mathrm{Kc})$, y entonces pudiera pensarse en que existe una combinación de Ks y Kc. En un artículo sobre estos temas Kliksberg (1999) considera ambos en el contexto de América Latina. En este caso los asocia como factores coadyuvantes pues constituyen las claves esenciales (cursivas en el original) del desarrollo.

El autor destaca la aplicación del concepto a partir de la idea de asociación (redes) basada en la confianza de Putnam (1993) y de reciprocidad y confiabilidad como base del orden público de Coleman (1990). Kliksberg (1999: 87-88) menciona a los siguientes autores y sus ideas sobre el concepto: Newton (1997) que privilegia los aspectos subjetivos como valores y actitudes que influyen en la relación entre individuos; Baas (1997) quien supone que tiene que ver con cohesión social en el marco de normas sociales; Joseph (1998) que lo ve como un conjunto de ideas, ideales, que sirven para movilizar energías a favor de causas públicas; Bullen y Onyx (1998) quienes lo identifican con redes sociales basadas en las ideas originales de confianza, reciprocidad y reglas para la acción. Por su parte Levi (1996) considera críticamente los hallazgos de Putnam y cree necesaria la participación del Estado para promover la creación de capital social. Mientras que Serageldin (1998), si bien acepta la relevancia del capital social en el desarrollo, se pregunta cómo se puede generar y utilizar y de qué modo materializarlo y estudiarlo empíricamente.

Claro, Kliksberg (1999: 88-89) hace referencia a estudios empíricos en diferentes países (incluyendo tres ejemplos en América Latina: Villa El Salvador en Perú; las Ferias de Consumo Familiar en Venezuela, y el 
presupuesto municipal participativo de Porto Alegre, Brasil) y destaca la metodología seguida para tratar de comprobar la aportación de capital social en los esfuerzos de desarrollo y comportamientos sociales dirigidos a la vida comunitaria, la productividad agrícola, la educación primaria, el cumplimiento de normas legales y fiscales así como el desempeño de la burocracia, etc. Pero en algunos estudios identifica el papel que juega la familia en el desarrollo de capital social y como éste, por un lado, permite aminorar problemas sociales y económicos, así como de salud y, por otro, aumentar la capacidad para enfrentar riesgos y crisis inesperadas. Insiste en que "la cultura cruza todas las dimensiones del capital social de una sociedad" (Kliksberg, 1999: 90).

Aquí habría que reconocer entonces el esfuerzo que representa para el Estado no sólo la educación sino crear y valorar cultura(s), desde una perspectiva amplia local y nacional, y así facilitar el desarrollo del capital social comunitario. De acuerdo con Kliksberg (1999: 97), la base de estas experiencias, si quisiéramos generalizar, ha sido la creación de confianza entre los distintos actores, la participación organizada de la comunidad, y una concepción de los valores que sirvió de motivación y orientación en el comportamiento comunitario. Nos parece que en el caso de los CDC el esfuerzo por parte del Estado en la creación de espacios de socialización e interacción entre vecinos es digno de destacarse, a pesar de limitaciones que identificamos de carácter financiero, físico, operativo, etc., en otras partes de nuestra evaluación. En efecto, la atención de la salud, la oferta de muy variados cursos de capacitación y la respuesta a las diversas iniciativas de los usuarios, ${ }^{22}$ en estos espacios antes inexistentes, han despertado entusiasmo, sentimientos de solidaridad, cooperación y reciprocidad, como se concluye de los grupos focales. Lo cual, como señalan coincidentemente los autores citados, constituye la simiente del capital social.

En los apartados anteriores presentamos los resultados de los grupos focales incorporando comentarios que creemos ponen en perspectiva la construcción teórica del concepto. En esta parte del texto reflexionamos acerca de los hallazgos derivados de las opiniones y percepción que afloraron en los grupos focales y sugerimos una estrategia hacia afuera que, con las particularidades de cada caso, pudiera estimular la participación de la población en el ámbito de influencia de cada CDC.

Una primera lectura fue que para los usuarios de los CDC los beneficios en estos rubros no son del todo significativos. Es decir, no sienten los efectos económicos concretos y tangibles de sus nuevas actividades y relaciones, y no parecen entender el alcance o el poder de actuar colectivamente. Por

\footnotetext{
${ }^{22}$ Relacionadas con expresiones artísticas, recuperación de tradiciones, prácticas culinarias, etc., entre otras.
} 
ejemplo, las usuarias perciben cambios sobre todo en el plano personal y familiar, así como en el mejoramiento de algunos aspectos de su colonia o barrio. Sin embargo, estos beneficios forman parte de la creación y fortalecimiento del capital humano y de la construcción de capital social, y creemos que contribuyen en el proceso de su consecución.

En este sentido, la influencia de los CDC en la formación de capital humano se encuentra en una etapa inicial. Se reconocen pequeñas mejoras en su economía doméstica, pero no se reportan aumentos significativos en los ingresos que permitan elevar el nivel de vida de las familias. Los CDC tienen un área de oportunidad: ofrecer cursos y talleres más específicos y acordes con las características de la población a la que se dirigen.

En relación con la creación de capital social, este proceso se encuentra también en una fase inicial caracterizada por el incipiente fortalecimiento de los vínculos sociales (figura I).

Otros beneficios de la asistencia a los cursos y talleres que se perciben de gran ayuda es el apoyo mutuo que surge entre vecinos, lo cual indica el fortalecimiento de vínculos sociales y el surgimiento de redes entre los mismos beneficiarios de los CDC.

La percepción de los prestadores de servicios que participaron en los grupos focales es que no sólo se están creando redes informales entre los

\section{Figura I}

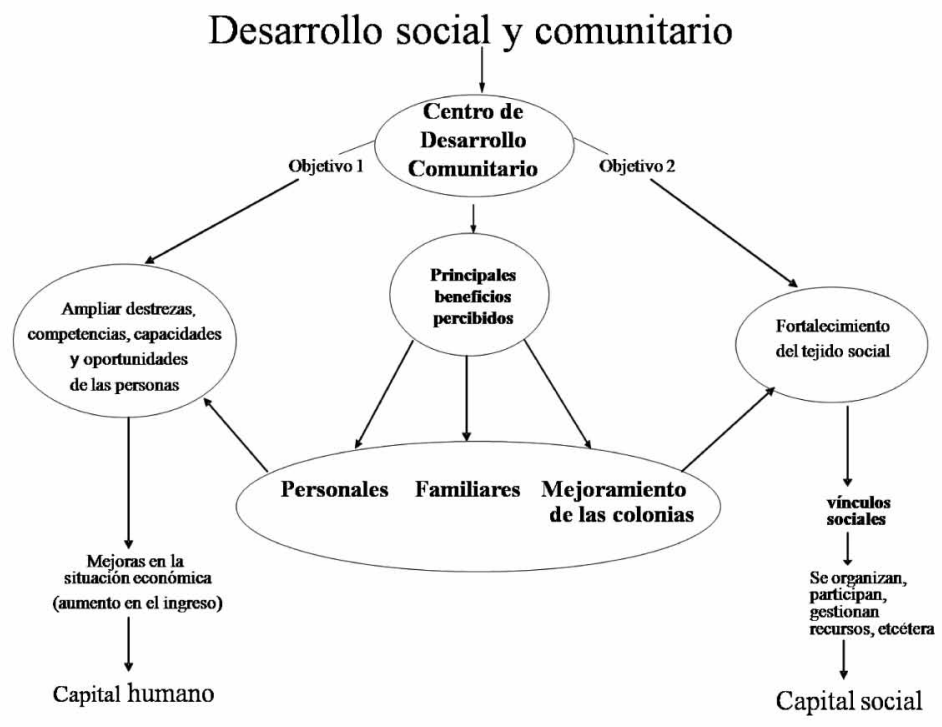

Fuente: Elaboración propia a partir del conjunto de CDC incluidos en el trabajo, modificado de la muestra original diseñada por la Dirección General de Geoestadística y Padrones de Beneficiarios (DGGPB) de la Sedesol. 
asistentes a los cursos y talleres, sino que ciertos servicios, como la atención psicológica, contribuyen adicionalmente a mejorar el desempeño escolar de los niños, sensibilizar a las mujeres de su condición de género, la importancia de una relación responsable y de respeto entre la pareja y dentro de la familia, al promover cambios conductuales.

Aunque el principal beneficio reportado es en el ámbito personal y familiar, también se consignan mejoras en la organización comunitaria. Sin embargo, el fortalecimiento de los vínculos sociales derivados de la interacción cotidiana que ocurre en los centros, debe complementarse con la promoción de actividades comunitarias extramuros por parte del CDC. Hasta ahora, el efecto de estos centros ha sido mucho más importante para el desarrollo personal de los usuarios y para mejorar la convivencia familiar, quedando en un segundo plano su efecto en el fortalecimiento del tejido social basado en relaciones comunitarias intensas y una sólida organización vecinal capaz de tomar en sus manos la conducción de los centros.

El reto para elevar la eficiencia y eficacia de las tareas del CDC tiene que ver con la planeación de sus actividades, incorporando la participación de la sociedad. Los CDC tienen que poner en marcha (o incrementar) campańas y/o actividades que promuevan el involucramiento y participación de la comunidad, como pueden ser la organización de exposiciones, ferias, concursos, eventos deportivos, tianguis culturales, actividades lúdicas, recitales y otro tipo de eventos especiales que fomenten la convivencia de los usuarios más allá de cursos y talleres a los que no concurre toda la población objetivo. Asimismo, se deben inducir labores colectivas para mejorar la imagen de la colonia, por ejemplo campañas de reforestación, limpieza, vigilancia, mejoramiento urbano, etcétera. Sólo así podrá hablarse de que los CDC están contribuyendo a la creación de capital social en el sentido de ampliar la membresía, más allá de la familia y de los vecinos, y extenderla a la creación de asociaciones voluntarias que respondan a problemas locales y comprometan a los individuos con su comunidad y la sociedad en general. Lo anterior redundará finalmente en ciudadanos con sentido de responsabilidad y compromiso, que son los actores que podrán mejorar el desempeño económico e impulsar la prosperidad local.

\section{Agradecimientos}

Queremos agradecer a los dictaminadores anónimos, quienes con sus muy pertinentes seńalamientos nos permitieron mejorar el trabajo. 


\section{Anexo}

\section{Protocolo que guió la organización y realización de los grupos focales}

Para el desarrollo de los grupos focales en campo se requirió la presencia de un moderador, que fue la persona que dirigió el grupo y propició la participación de todos los asistentes. También se contó con una persona que tomara notas de lo que se discutió. Fue necesario aclarar algunos términos a usar al inicio de la discusión para efectos de que todos los participantes hicieran referencia a los CDC en el mismo sentido. Así, a las actividades que lleva a cabo el centro se les denomina "servicios, cursos y talleres". Los servicios se refieren a todas aquellas actividades como salud (medicina general, odontología, optometría, oftalmología, psicología, etc.), comedores (servicios de alimentación para los usuarios), internet, asistencia legal, servicios de biblioteca, guardería, etc. Los cursos y talleres se refieren a actividades en las que se imparte alguna clase o se enseña algún oficio, técnica artística o deportiva. Algunos ejemplos son las clases de idiomas, primaria, secundaria, preparatoria, karate, así como los talleres de manualidades, cocina, cerámica, carpintería, confección, etcétera.

Los guiones para orientar la discusión se diseñaron y estructuraron de manera que se obtuviera la información necesaria para poder cumplir con los objetivos mencionados al inicio de este apartado. De los grupos focales de usuarios se obtuvo información sobre la calidad y efecto de los servicios ofrecidos por los CDC, su estado físico y equipamiento, así como la oferta de servicios. En cuanto a los organizados con los prestadores de servicios, se discutieron sus percepciones respecto de la utilidad de los CDC, la oferta de servicios y las características de los usuarios.

Cada moderador debía notar la particularidad de su grupo, sin embargo, las siguientes instrucciones generales aplicaron en todos los casos:

- El grupo debió contar con la asistencia mínima de cuatro participantes y máximo de ocho.

- Fue importante en todos los casos contar con un espacio adecuado, para no tener distracciones (ruidos, personas entrando y saliendo, así como buena audición).

- Una vez iniciado el ejercicio y la dinámica, no pudo incorporarse nadie más al grupo.

- Se establecieron algunas reglas, por ejemplo, en el caso de que algún participante se presentara con su(s) hijo(s) pequeño(s), y con el fin de evitar distracciones, la regla fue que estos se quedasen en la guardería o que alguien se encargara de ellos. Adicionalmente y con el propósi- 
to de que no se interrumpiera la dinámica de grupo, se recurría a llamar la atención de algún participante sin distraer a los demás.

- Al inicio de la sesión se entregó a cada participante una etiqueta con su nombre, para poder dirigirse a ellos de esa manera y lograr un ambiente más amable. Sin embargo, cuando esto representaba una situación incómoda para los participantes se evitó hacerlo.

- Durante el desarrollo de la sesión, los moderadores tuvieron la flexibilidad de omitir, agregar o modificar preguntas si fuese necesario.

- Se explicó a los participantes que durante el ejercicio ellos constituían un grupo que intercambia opiniones y cada quien aprende de las respuestas de los demás o reacciona con ellas. Que no se trataba de entrevistas individuales simultáneas sino que se esperaba que la dinámica de grupo promoviera la discusión entre todos.

- Con el moderador se acordó que en caso de que el grupo no fuese muy participativo, se podrían trabajar algunas preguntas (como qué les gusta y qué no les gusta) con tarjetas; es decir, se pediría a los participantes escribir una respuesta que pudiera luego leerse en voz alta o pasarla al moderador, y a partir de ello ir profundizando en otros temas. Asimismo, tener en cuenta preguntas de ayuda como las siguientes podría resultar fundamental para el éxito del grupo:

-No me quedó muy claro. ¿Podrías explicar a qué te refieres?

-¿Alguien podría dar un ejemplo?

-¿Alguien comparte esta experiencia?

-¿Alguien tiene una perspectiva similar (diferente)?

-Parece que todos entendieron lo que $\mathrm{X}$ dijo, pero a mí no me ha quedado claro, ‘alguien puede ayudarme?

- Quienes tomaban nota, observadores, gente de apoyo, no debían hablar. Si tenían algún cometario que hacer al moderador, debían hacérselo llegar por medio de una tarjeta (por ejemplo, si se está extendiendo demasiado en una pregunta, o si debe regresar a un punto específico, etcétera).

- Quienes tomaban nota debían registrar tanto lo que se dijera, como el fraseo utilizado, el tono de voz y el lenguaje no verbal.

- Fue importante que no se encontrara presente alguna autoridad local o federal para que los participantes (usuarios y prestadores de servicios) no sintieran presión o influencia de algún tipo.

- Fue necesario grabar la sesión para poder realizar el informe.

- Los apoyos logísticos necesarios fueron: etiquetas adheribles para identificar el nombre de los participantes, sillas suficientes (y una mesa 
si se consideraba necesaria), hojas blancas, lápices y plumas, así como una grabadora.

\section{Bibliografía}

Ander-Egg, Ezequiel (2006), La problemática del desarrollo de la comunidad, Lumen, Buenos Aires.

Bebbington, Anthony J. (2005), "Estrategias de vida y estrategias de intervención: capital social y programas de superación de la pobreza”, en Irma Arriaga (ed.), Aprender de la experiencia: el capital social en la superación de la pobreza, Comisión Económica para América Latina y el Caribe, Santiago, pp. 21-46.

Bebbington, Anthony J. (2007), "Social capital and development studies II: can Bourdieu travel to policy", Progress in Development Studies, 7 (2), Sage, Thousand Oaks, pp. 155-162.

Becker, Gary S. (1993), Human Capital: A Theoretical and Empirical Analysis with Special Reference to Education, University of Chicago Press, Chicago.

Bourdieu, Pierre (1985), “The forms of capital”, en J. Richardson (ed.) Handbook of Theory and Research for the Sociology of Education, Nueva York, Greenwood, pp. 241-258.

Coleman, James (1966), The Coleman Report: Equality of Educational Opportunity, US Government, Washington.

Coleman, James Samuel (1990), Foundations of social theory, The Belknap Press of Harvard University Press, Cambridge-Londres.

Cortés, Fernando (2008), Algunos aspectos de la controversia entre la investigación cualitativa y la investigación cuantitativa, El Colegio de México, México.

De Vries, David (1986), Surveys in Social Research, Allen \& Unwin, Londres. 
Durston, John (2000), ¿Qué es el capital social comunitario?, CEPaL, Santiago, <http://www.cepal.org/publicaciones/xml/5/4885/lcl1400. pdf $>, 8$ de febrero de 2011 .

Garrocho, Carlos y Carlos Brambila (2008), "Satisfacción de las beneficiarias con el Programa de Desarrollo Humano Oportunidades. Una evaluación cualitativa”, Economía, Sociedad y Territorio, vII (28), El Colegio Mexiquense, Zinacantepec, pp. 921-964.

Gómez-Hernández, Esperanza (2008), "Geopolítica del desarrollo comunitario: reflexiones para el trabajo social”, Ra Ximhai, 4 (3), Universidad Autónoma Indígena de México, Mochicahui, El Fuerte, Sinaloa, pp. 519-542.

Graizbord, Boris (1999), "Planeación urbana, participación ciudadana y cambio social”, Economia, Sociedady Territorio, II (5), El Colegio Mexiquense, Zinacantepec, pp. 149-161.

Graizbord, Boris, Mariana Castillo, José Luis González y Adriana Larralde (2008), "Los programas sociales de combate a la pobreza urbana: Los Centros de Desarrollo Comunitario apoyados por el Programa Hábitat-Sedesol", ponencia presentada en la IX Reunión Nacional de Investigación Demográfica en México, 8-11 de octubre, Mérida, Yucatán, mimeo.

Johnston, Ron J. (2000), Gregory Derek, Geraldine Pratt y Michael Watts (eds.), The Dictionary of Human Geography, Blackwell, Oxford.

Kliksberg, Bernardo (1999), "Capital social y cultura, claves esenciales del desarrollo", Revista de la CEPAL, 69, CEPAL, Santiago, pp. 85-102.

Martínez-Miguélez, Miguel (2007), Evaluación cualitativa de programas, Trillas, México.

OCDE (Organización para la Cooperación y el Desarrollo Económico) (2002), "Glossary of Key Terms in Evaluation and Results-Based Management", OCDE-DAC, París.

Pearce, David (1992), The MIT Dictionary of Modern Economics, The MIT Press, Cambridge. 
Pérez-Serrano, Gloria (1998), Investigación cualitativa. Retos e interrogantes, La Muralla, Madrid.

Portes, Alejandro (1998), "Social Capital: Its Origins and Applications in Modern Sociology”, Annual Review of Sociology, 24, Annual Reviews, Palo Alto, CA., pp. 1-24.

Putnam, Robert (1993), “Bowling Alone: America’s Declining Social Capital", Journal of Democracy, 6 (1), Johns Hopkins, Baltimore, pp. 65-78.

Putnam, Robert, Robert Leonardi y Raffaella Y. Nanetti (1993), Making Democracy Work: Civic Traditions in Modern Italy, Princeton University Press, Princeton.

Putnam, Hilary (1996), "La objetividad y la distinción ciencia-ética”, en Martha Nussbaum y Amartya Sen (comps.), La calidad de vida, Fondo de Cultura Económica, México, pp. 193-210.

Scott, John y Gordon Marshall (2005), Oxford Dictionary of Sociology, Oxford University Press, Oxford.

Sedesol (Secretaría de Desarrollo Social) (2005), Modelo de operación para los centros de desarrollo comunitario, Sedesol, México.

Sedesol (Secretaría de Desarrollo Social) (2007), Términos de referencia para la evaluación de la operación y los servicios ofrecidos en los Centros de Desarrollo Comunitario apoyados por el programa Hábitat de 2004 a 2009, Secretaría de Desarrollo Social, México.

Ware, Carolina (1966), "Criterios para el análisis de propuestas para el desarrollo de la comunidad", en BID, Desarrollo de la comunidad: teoría y práctica, Banco Interamericano de Desarrollo, México, pp. 263-295.

Zall-Kusek, Jody y Ray C. Rist (2004), Ten Steps to a Results-Based Monitoring and Evaluation System, Banco Mundial, Washington.

Recibido: 16 de abril de 2010. Reenviado: 14 de febrero de 2011. Reenviado: 24 de julio de 2011. Aceptado: 29 de agosto de 2011. 
Boris Graizbord. Es doctorado en geografía social por la London School of Economics and Political Science, Inglaterra (1975-1977); maestro en geografía urbana por la Universidad de Durham, Inglaterra (1973-1974), y arquitecto (1965) por la Escuela Nacional de Arquitectura de la Universidad Nacional Autónoma de México (UNAM) (1958-1962). Es profesor-investigador en El Colegio de México; coordinador del Programa de Estudios Avanzados en Desarrollo Sustentable y Medio Ambiente (LEADMéxico) y miembro del Sistema Nacional de Investigadores (SNI), nivel III. Sus actuales líneas de investigación son: crecimiento urbano y metropolitano, desarrollo regional, geografía electoral, población y medio ambiente, contaminación urbano-industrial, transporte metropolitano y desastres naturales. Entre sus últimas publicaciones destacan: Geografía del transporte en el Área Metropolitana de la Ciudad de México, El Colegio de México, México (2008); en coautoría, Megacities and Climate Change. Sustainable urban living in a changing world, LEAD International-LEAD Mexico, (2008); "Mexico: Local Government in Federal Systems", en John Kincaid y Rupak Chattopadhyay (eds.), "Local Government in Federal Systems", vol. 4, Unity in Diversity learning from Each Other, Viva Books, Forum of Federations New Delhi, pp. 71-92 (2008); en coautoría, "Movilidad residencial en la Ciudad de México", Estudios Demográficos y Urbanos, 22 (2) (65), México, El Colegio de México, pp. 291-335 (2007); "Governing Metropolitan Regions in Mexico: From Theory to Practice", Dialogue on Federalism, vol. 6, Booklet Series, pp. 27-29 (2007); en coautoría, Relatoría taller "Zonas metropolitanas y gobiernos locales en sistemas federales”, Estudios Demográficos y Urbanos, 22, 3 (66), El Colegio de México, México, pp. 723-730 (2007).

Rocío González-Alva. Es doctora en estudios urbanos y ambientales por $\mathrm{El}$ Colegio de México (2005-2008); es maestra en estudios urbanos por El Colegio de México (2003-2005), y licenciada en planeación territorial por la Facultad de Planeación Urbana y Regional de la Universidad Autónoma del Estado de México (1997-2002). Actualmente es investigadora en el Proyecto "Estudio de Integración Urbano Regional de la Línea 12 del Metro", ins-unam. Ha colaborado en diversos proyectos como: Teletrabajo, cambio climático y políticas públicas en la ciudad de México; elaboración de la Agenda de Sustentabilidad Ambiental para la zmvm; Análisis y evaluación de la sostenibilidad del medio ambiente en México; evaluación de los centros de desarrollo comunitario apoyados por el Programa Hábitat; estudio para la elaboración de un ordenamiento territorial en Tlaxcala; asesoría para la elaboración de un manual de incorporación de suelo urbano a la vivienda de interés social; indicadores 
de la regularización y estimaciones de la irregularidad del suelo urbano en el Estado de México y acceso al suelo para las nuevas generaciones de los barrios y colonias de Chimalhuacán. Recibió el Premio a la Investigación 2006 otorgado por la Universidad Autónoma Metropolitana en el Área de Ciencias y Artes para el Diseño, por el trabajo en conjunto titulado, La ciudad de los caminos: el caso del corredor Tlaxcala-Puebla. Sus líneas actuales de investigación son: suelo urbano, movilidad residencial y medio ambiente urbano. Entre sus últimas publicaciones destacan: en coautoría, "Desajuste residencial, vivienda y empleo en la periferia de la Zмсм", en Guillermo Aguilar e Irma Escamilla (coords.), Periferia urbana: deteriorio y reestructuración metropolitana, UNAM-Miguel Ángel Porrúa, México, pp. 349-367 (2009); en coautoría, "Cambiándose de asentamiento irregular. El hábitat irregular y la movilidad residencial intraurbana en Chimalhuacán”, en Alfonso Iracheta y Susana Medina (coords.), Irregularidad y suelo urbano: ¡cómo incidir en las prácticas sociales y hacia dónde dirigir las políticas públicas en México para enfrentar el fenómeno?, El Colegio Mexiquense-Sedesol-un-Hábitat, México, pp. 211-237 (2008); "Movilidad residencial y mujeres en la Zona Metropolitana de la Ciudad de México", Horizontes, 12, Coespo-Gobierno del Estado de México, Toluca, pp. 16-21 (2007); en coautoría, "El nuevo Hábitat de la irregularidad territorial en el municipio de Chimalhuacán”, en Elías Huamán (ed.), Anuario de Espacios Urbanos (2006-1), UAM, A, México, pp. 247-271 (2006); en coautoría, "Análisis FODA del corredor urbano Tlaxcala-Puebla", en Óscar Terrazas (coord.), La ciudad de los caminos: el caso del corredor Tlaxcala-Puebla, UAM, AFomix, Gobierno del Estado de Tlaxcala-Conacyt, México, pp. 55-69 (2005). 